\title{
Biting the bullet: Fixing America's quiet epidemic of gun suicide
}

\author{
ZACKARY J. DRURY
}

\section{Abstract}

This article investigates the growing issue of firearm suicide in America. Each year, firearm suicides account for roughly two-thirds of all gun deaths in the United States. Despite this, the common gun control narrative focuses on mass shootings; acts that account for less than 1 per cent of all gun murders annually. Through a quantitative analysis of data drawn from various governmental and academic sources, it will be demonstrated that current legislative approaches do not present effective solutions to gun violence, nor do they address the much larger issue of firearm suicide. Through an investigation of suicide prevention literature and relevant international case studies, this paper will argue that alternative legislative approaches exist that can save lives, and curtail America's growing epidemic of firearm suicides.

\section{Introduction}

Today, gun violence has become synonymous with the United States of America (US). Brutal mass shootings_-Virginia Tech, Aurora, Sandy Hook, and now Orlando-are all too common in a country where individual liberty regularly trumps public safety in the gun debate. The statistics themselves are staggering. While gun sales continue to skyrocket across the country, the Centers for Disease Control and Prevention (CDC) (2014) reported 33,599 deaths from incidents of firearm-related violence in 2014 alone. This lethal dichotomy underlines the country's toxic relationship with firearms: a deeply engrained and beloved cultural institution, seemingly beyond rebuke in certain regions, which continues to have a devastating impact on an increasingly polarised partisan community. While such a stunning death toll would typically necessitate a response in any other field, legislative solutions for America's gun problem have never appeared less likely. Even in the fallout of major mass shootings, legislative lethargy has persisted, whether at the hands of obstructionist Republicans, well-funded gun lobbyists or conservative Supreme Court Justices. Beyond this, another factor has served to muddy the debate-an incoherent and polarising narrative that ignores data in favour of hot button topics such as the accessibility of assault rifles. To this end, the two most 
pressing issues are ignored: mainly, that current legislative approaches appear to have had little independent effect on the country's murder rate, and that nearly two-thirds of all firearm deaths in the United States annually are actually suicides. This startling figure serves to highlight a growing epidemic in America; one that is often ignored in the mainstream debate, but yet offers a rare opportunity for bipartisanship through legislation that could save thousands of lives a year.

This paper will argue that the current gun control narrative focuses on pursing ineffective legislation that is not reflective of the larger issues associated with gun violence in America. Further, this paper will argue that there are legislative solutions available that are both effective in preventing loss of life and tenable enough to pass in a fractured and polarised US Congress. This article will approach this over two sections. After a brief overview of the relevant methodology, the first section will employ a quantitative analysis to show that assumptions in the current gun control narrative are demonstrably incorrect, and that firearm suicides represent the vast majority of gun deaths in America. The second section will present an overview of suicide prevention literature and relevant international case studies to discuss the viability of legislative approaches that specifically target firearm suicide. The section will conclude with a brief overview of current legislative remedies before the US Congress, and outline potential areas of further reform. As such, this article will demonstrate that the current gun control debate does not accurately reflect the wider issues associated with gun violence in America, and that a new framework and focus for legislation is necessary to save lives. This new approach is supported not by a polarised narrative with demonstrably false assumptions, but rather a strict analysis of relevant data. Further, it offers alternative approaches to gun legislation that are both demonstrably effective and palatable to both sides of the political spectrum.

\section{Methodology}

The first section of this article has primarily relied on statistics collected from a variety of government and academic sources. Predominately, primary data has been sourced from the Federal Bureau of Investigation (FBI), the CDC, the Bureau of Justice Statistics (BJS), the Bureau of Labour Statistics (BLS), Congressional Record service reports and census reports. This data has been collated and used to graph historic trends in state-level and federal-level gun violence, and will be referenced throughout. Further supplementary and secondary data has been sourced from academic journals and public surveying reports, and will be referenced accordingly. The second section of this article will investigate a broad range of suicide prevention literature and international case studies to present effective legislative approaches to curtail this growing epidemic. By leaning solely on the aforementioned data and analysis, this article serves to bypass the emotional rhetoric often associated with the gun control debate in favour of discussing public health legislation that will best benefit the general public. 


\section{The realities of American gun violence}

Contrary to the rhetoric normally employed by gun control advocates, there has been significant decline in violent crime and gun murders over the last two decades. Traditionally, citizens of the United States have always killed each other at a far higher rate than other Western countries (Fischer, 2011). Furthermore, the majority of murders in America are committed with guns; roughly 70 per cent of all murders in 2013 were caused by firearms (Ehrenfreund, 2015). However, as Figure 1 demonstrates, the firearm homicide rate in America has rapidly and almost continuously declined since the early ' 90 s. This remarkable drop has also contributed to overall homicide rates slowly returning to the same level as the 1960s; the lowest point in the country's modern history (Fischer, 2011). This trend has also extended to non-fatal firearm crimes, with the number of gun-assisted assaults, robberies and rapes in 2014 plummeting to a quarter of their 1993 figures (Krogstad, 2015). Further, despite significant media coverage, evidence suggests that America is in fact not currently suffering through an epidemic of mass shootings. Figure 2 shows that over the 1999-2013 period, there was only a minor increase in the frequency and deadliness of mass shooting incidents. More importantly, mass shootings accounted for less than 1 per cent of the overall gun homicide rate in 2013. As such, it is clear that mass shootings have remained relatively sporadic in both regularity and deadliness over the period. This overall decline in firearm crime-from mass shootings to robberies-stands in stark contrast to the classic gun control narrative, which often uses instances of gun violence to lobby for increased regulation and oversight.

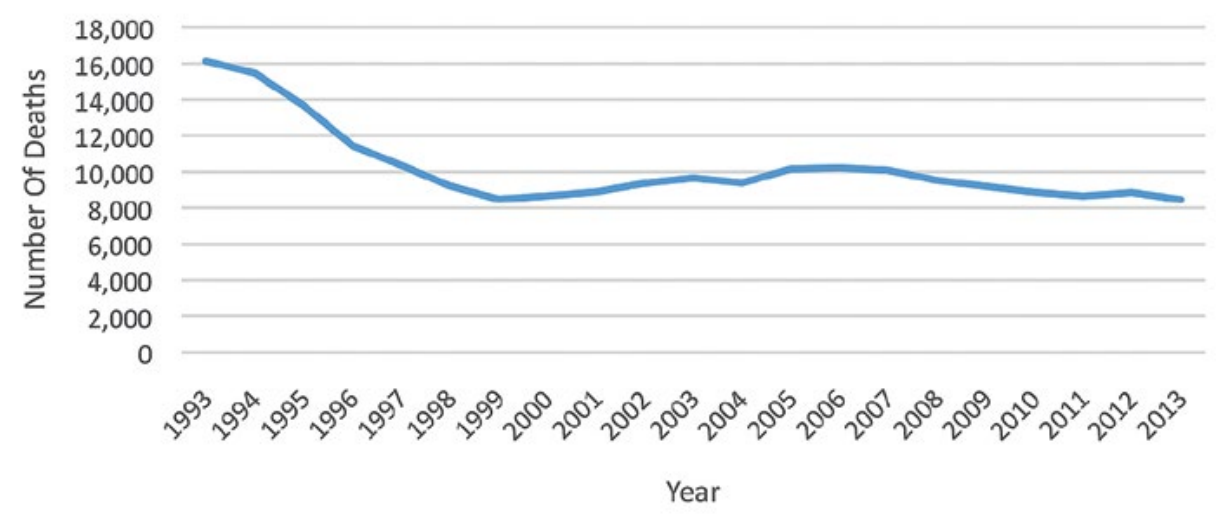

Figure 1: Gun homicides, 1993-2013.

Source: Federal Bureau of Investigations Uniform Crime Reporting (2014). 


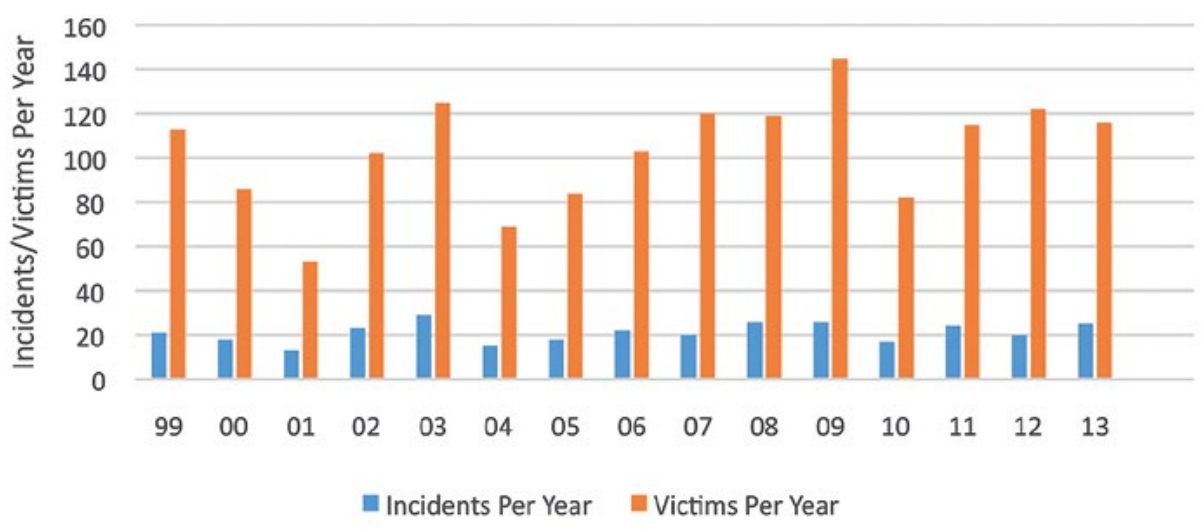

Figure 2: Mass shootings, 1999-2013.

Source: Krouse (2015).

Despite this downward trend in gun violence, the available data does not support the contention that this decline has been affected by any previous gun control legislation. This relates to both efforts to restrict access to guns, and also to regulate the sale of particular types of firearms. The causal link between widespread ownership and a higher firearm murder rate is demonstrably incorrect. By analysing the per-state gun homicide data for 2013, Figure 3 demonstrates that there is no relationship between increased gun ownership and higher frequencies of gun homicides. This finding is at odds with a substantial amount of literature, but discrepancies can be explained by two major variations in methodology. Primarily, gun death statistics often bundle all types of firearm-related deaths together (Sullum, 2015). When gun homicide rates are isolated, there is clearly no correlation between ownership and an increased death toll. Additionally, a number of papers introduce controls for factors such as poverty, urbanisation, unemployment and drug abuse into their analysis (Miller et al., 2002; Siegel et al., 2013). However, the primary flaw in this approach is that controlling for socioeconomic and environment factors blatantly ignores the motivating factors of the crime. Without these factors, the logic flows that merely possessing a firearm makes the owner more inclined to commit homicide- a fallacy that unnecessarily distorts the realities of gun crime. As such, this methodological approach was not employed in this article, and instead direct state-by-state comparisons were used. While this article certainly doesn't venture as far as to suggest America's ubiquitous firearms are creating an overall safer environment, an analysis of data clearly shows that increased ownership does not affect the gun homicide rate. 


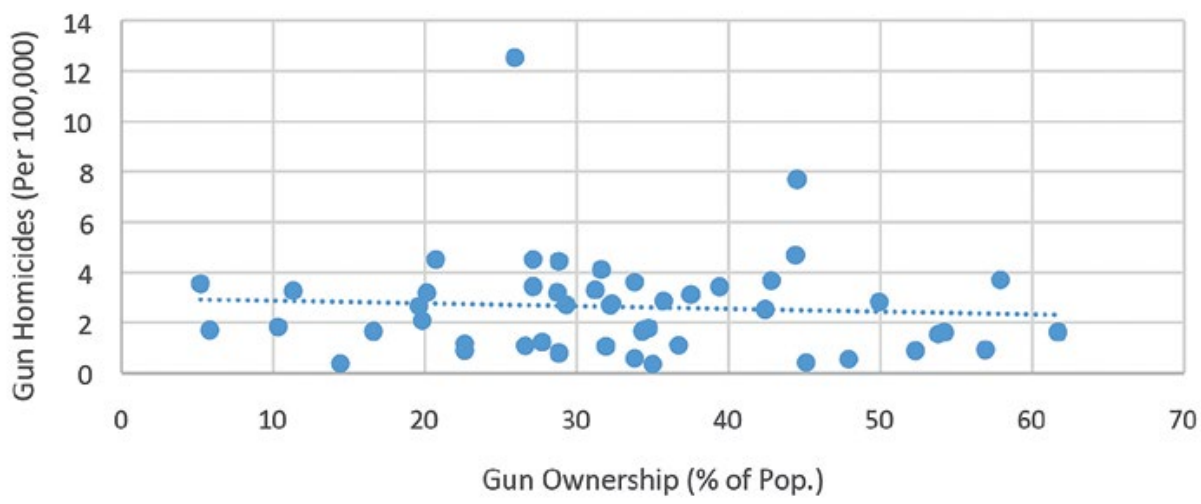

Figure 3: Gun homicide and gun ownership, 2013 (does not include FL, AL or IL).

Source: Federal Bureau of Investigations Uniform Crime Reporting (2014) and Kalesan et al. (2015).

Furthermore, efforts to regulate and restrict the sale of firearms have proven to be entirely ineffective in preventing gun homicides. This is due to two main factors: the guns often targeted by gun control advocates are rarely used in crime, and evidence suggests that the vast majority of crimes are committed with illegally obtained weapons. Figure 4 shows a breakdown of the gun homicide rate by weapon. The data shows that the overwhelming majority of gun homicides are committed with handguns, with barely one in 10 dying at the hands of rifles, assault rifles or shotguns. Clearly, efforts to ban assault rifles and other automatic weapons are ill-informed; while the medias fascination with mass shootings disproportionately represents assault rifles, the specific 1994-2004 Federal Assault Weapon Ban did little to effect the homicide rate (Beckett, 2014). Even legislation that specifically targeted handguns was unsuccessful; Monroe (2008) found substantial evidence to suggest that the Brady Handgun Act did little to significantly impact the homicide rate over the last two decades. This is primarily because the majority of crimes are committed with illegally obtained firearms that bypass the background check system. A Department of Justice (2001) report found that only 14 per cent of inmates who had used a gun in their crime had purchased it legally from a store. Rather, 40 per cent had acquired a gun from family or friends, while the remainder had either stolen the weapon or bought it illegally off the streets. While attempts to regulate and restrict the sale of certain firearms have dominated legislative efforts in recent times, it is clearly evident that these efforts have not substantially impacted the homicide rate in America to date. 


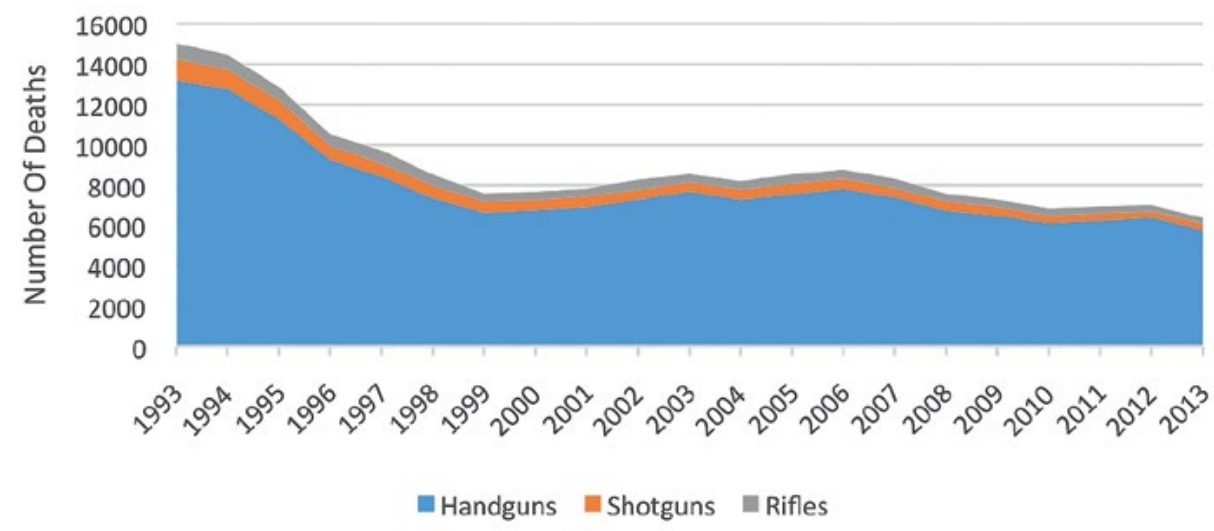

Figure 4: Gun homicide by weapon, 1993-2013.

Source: Federal Bureau of Investigations Uniform Crime Reporting (2014).

There are a number of alternative hypotheses offered to explain both the overall decline in violence since the early 1990s, and the remaining prevalence of gun homicides in America. Primarily, these explanations shift the blame for gun crime from general possession to social, economic and environmental factors. Levitt (2004, 176-183) contends that an increased police presence, the abnormally high incarceration rate, a decline in crack cocaine and alcohol usage, and the legislation of abortion in the early 1970s are factors that influenced the decrease in crime rates during the 1990s. Reyes's (2007) argument that the decline was the result of the phasing-out of lead in gasoline and house paint due to the passage of the Clean Air Act 1970 is also surprisingly persuasive. Additionally, Florida (2011) found strong correlations between reduced gun violence and high levels of college education and 'white collar' jobs within a community. Importantly, these hypotheses all disregard gun ownership as a driving factor in violence in favour of social, economic and environmental factors - an approach that can be extended to current gun homicide trends. Figures 5-6 compare state-by-state per capita homicide rates with two different social and economic variables: one being statewide levels of unemployment, and the other the percentage of the population below the nominal American 'poverty' income line. Both figures chart a strong correlation between gun homicide and social disenfranchisement. While a direct causal relationship between these variables may be tedious, these factors were chosen as broad indicators of how gun crime can be convincingly associated with factors outside of mere possession. These alternative hypotheses are important and cogent, particularly when considering that the traditional explanation for gun violence clearly falters when the historic low firearm homicide rate is compared with current record-breaking rate of gun ownership. 


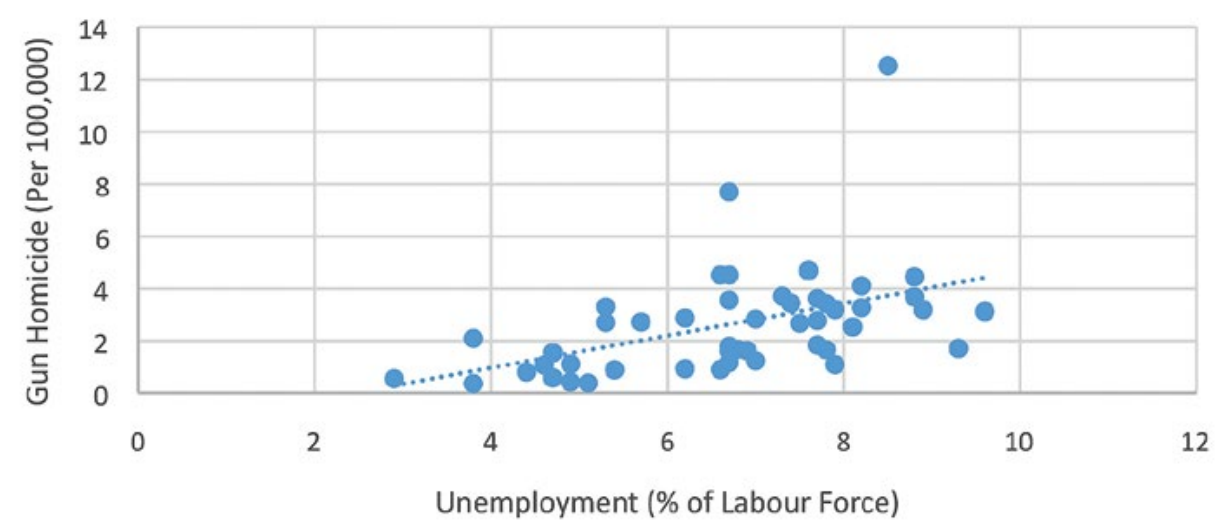

Figure 5: Gun homicide and unemployment, 2013 (does not include FL, $A L$, or IL).

Source: Federal Bureau of Investigations Uniform Crime Reporting (2014) and United States Department of Labor (n.d.).

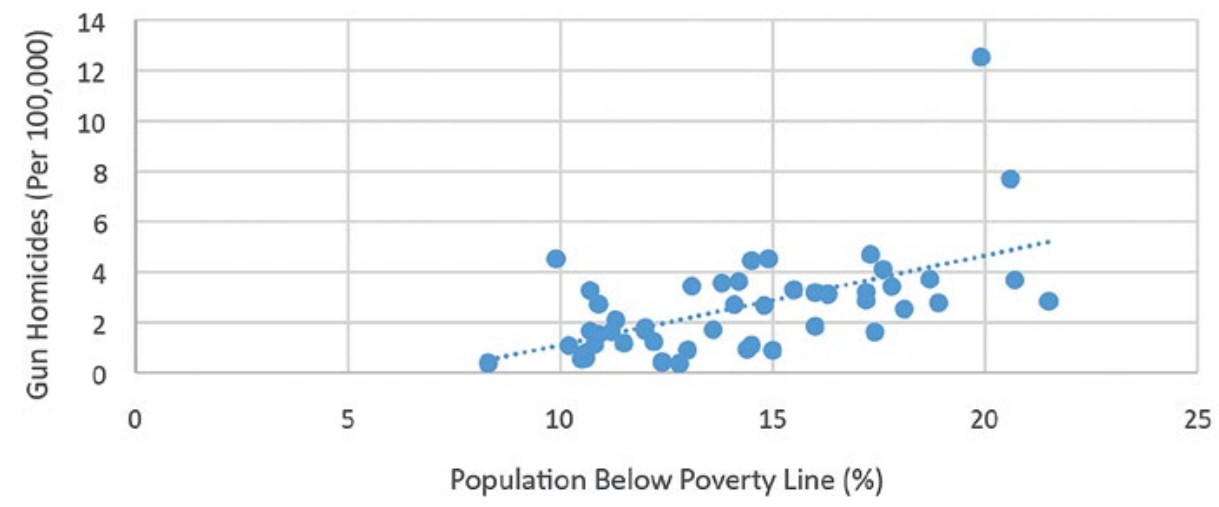

Figure 6: Gun homicide and poverty, 2013 (does not include FL, AL, or IL). Source: Federal Bureau of Investigations Uniform Crime Reporting (2014) and Short (2014).

Firearm suicides account for the largest portion of gun deaths in America. As Figure 7 clearly demonstrates, firearm suicides have broken rank from other categories of gun crime, and have remained stubbornly high over proceeding decades. Today, more than 60 per cent of firearm deaths in America are intentional suicides (SangerKatz, 2015). Further, the suicide rate has reached a near 30-year high, with a sharp increase in fatalities amongst 10-75-year-olds of both genders since 2006 (Curtin et al., 2016). The majority of successful suicide attempts in America are committed with guns; in 2014, gun suicides accounted for 55.4 per cent of all male suicide fatalities, and 31.4 per cent of all female suicide fatalities (Curtin et al., 2016). Worryingly, an investigation of suicide victim data shows a clear correlation between higher ownership and an increased death toll. Figure 8 compares statewide gun ownership with the per capita rate of gun suicides. The analysis shows a strong 
correlation between higher gun ownership and increased incidents of firearm suicide. Studies conducted by the Brady Center (2015) reveal that of the five states with the highest suicide rates in America, four of them have a gun ownership rate of over 50 per cent. The prevalence of firearms also effects the overall suicide rate. Figure 9 shows that higher firearm ownership leads to an overall increase in the number of suicide fatalities in a state. These statistics clearly demonstrate a growing epidemic with a strong correlation to the ownership and availability of firearms; a statement that cannot be made with regards to the nation's homicide rate. Evidently, there is a clear and strong correlation between higher rates of gun ownership and a higher overall suicide rate.

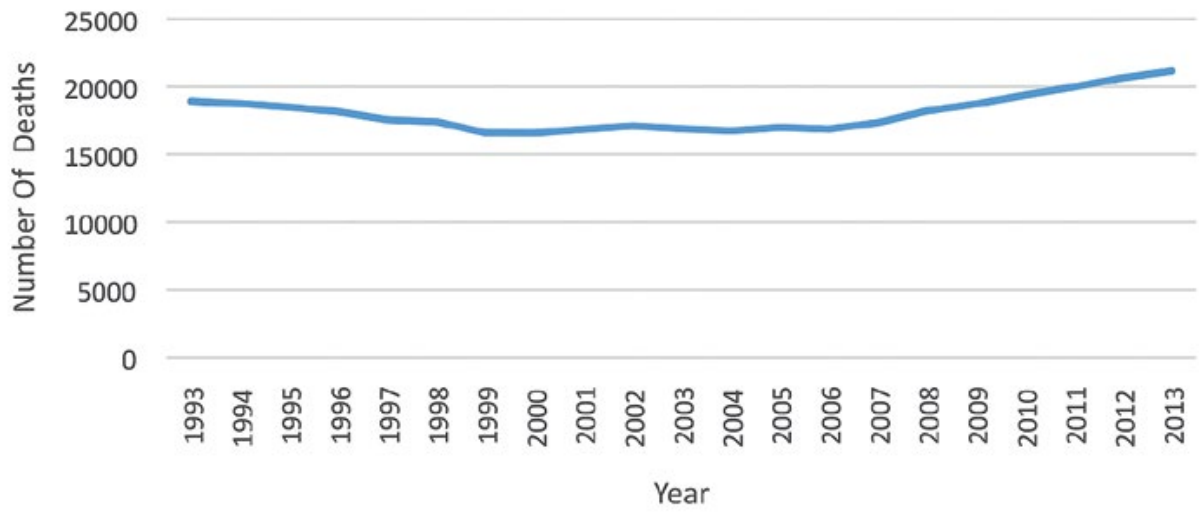

Figure 7: Gun suicide, 1993-2013.

Source: Centers for Disease Control and Prevention (2014).

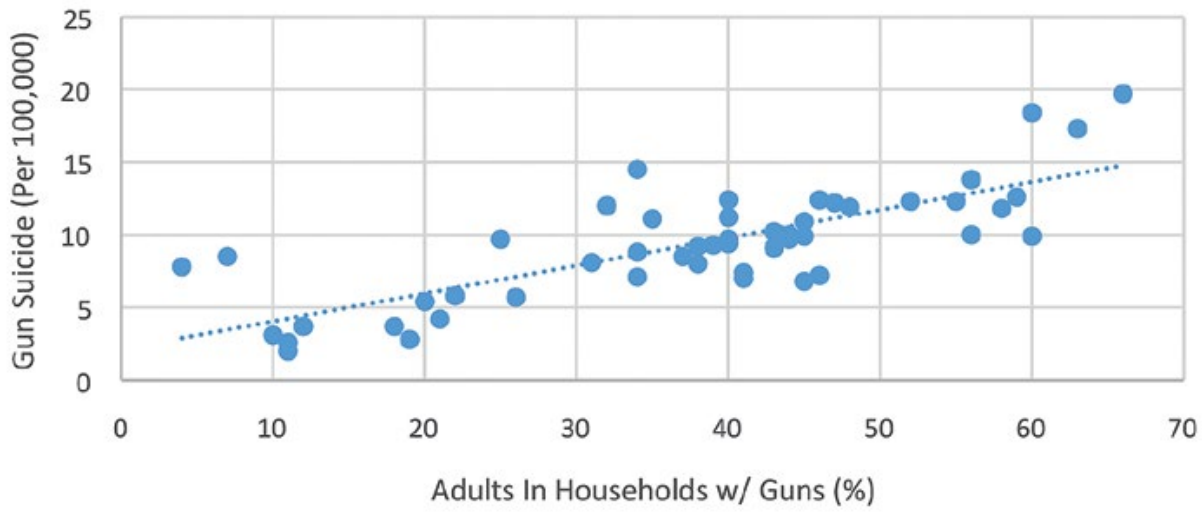

Figure 8: Gun suicide and gun ownership, 2013 (does not include DC). Source: Centers for Disease Control and Prevention (2014) and Miller et al. (2013). 


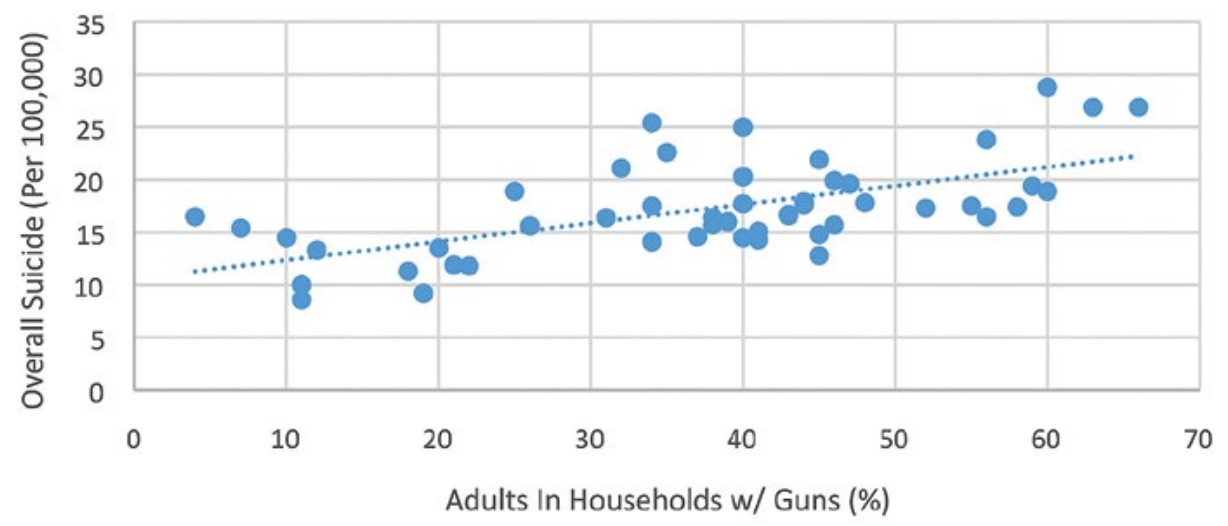

Figure 9: Overall suicide and gun ownership, 2013 (does not include DC). Source: Centers for Disease Control and Prevention (2014) and Miller et al. (2013).

Clearly, gun suicides play a quiet but substantial role in American firearm violence. While mass shootings and murders have dominated the debate for so long, the issue of gun suicide is often ignored. An analysis of the available data-devoid of emotion or rhetoric-clearly shows that traditional gun control legislation has done little to curb the country's high firearm homicide rate. Legislation that targets restriction and regulation has failed to provide tangible results, while alternative hypotheses for violence rooted in social disenfranchisement and economic disparity offer far stronger explanations for the sharp decline of gun crime over the last two decades. Most importantly, the data clearly shows that the number of gun murders in America pales in comparison to the number of gun suicides. Not only does this analysis dispel a number of key assumptions often held as gospel truth in the gun control narrative, it also provides an avenue for potential solutions. The zero-sum nature of politics means that it is pointless to expend time, effort and political capital on policies that are unpassable, ineffective and unrepresentative of the larger issues. By showing a clear link between increased gun ownership and increased suicide- a connection that is demonstrably absent when referring to gun homicides-the path forward for legislation becomes more apparent. The following section will investigate why gun suicide is such an issue in America, and how this epidemic can be curtailed. Predominately, it will be shown that mental health treatment in America has often been the inadvertent victim of well-intentioned legislation, and that means prevention can substantially affect both the firearm and overall suicide rates. As such, the section will argue that there are avenues to pursue suicide prevention legislation that are possible and politically palatable in the future. 


\section{Suicide, mental health and reform}

There is a stark causal link between gun ownership and higher suicide rates, primarily for the reason that guns are an incredibly effective method of suicide. The previous section outlined the strong correlation between gun ownership and suicide, but the Harvard School of Health goes further with its 'Means Matters Campaign'. Primarily, the campaign has contributed a considerable sum of literature that suggests a direct causal link between gun ownership and higher instances of gun suicide. First, roughly 85 per cent of all firearm suicide attempts are successful, whereas suicide by intentional pill overdose-the most common method employed in the US — is lethal only 2 per cent of the time (Vyrostek et al., 2001). Second, there is no significant difference in the number of suicide attempts between states with lower or higher gun ownership, but a significant increase in the number of fatalities (Miller et al., 2013). Third, a study found that gun owners were no more likely to have mental health issues than non-gun owners, and thus the external drivers of suicide were equally common in both sets (Miller et al., 2009). This evidence points to a direct causal link between the presence of firearms, and increased instances of suicide. As such, the 'Means Matters Campaign' advocates for legislative solutions that are born from suicide prevention literature. By creating barriers between at-risk individuals and firearms - the most lethal means of suicide available - and by supporting the mental healthcare system to treat those suffering from mental health illnesses, means prevention can save lives. The remainder of this section will discuss how means prevention can work, and how legislation can assist this.

Current literature suggests that restricting the ability of at-risk individuals to access firearms should be a priority for legislators. While any effort to regulate firearms is often met with strong rebuttal from firearm industry and lobbyist groups, there has consistently been strong bipartisan support for measures that seek to achieve this goal (Pew Research Center, 2015). Nuance in this debate is important; as Keith Hotle, a Suicide Prevention Team Leader in Wyoming, said in a recent interview, 'it's not about taking away people's guns, it's about how to deal with folks in a temporary crisis' (Tavernise, 2013). In these emergency situations, it is important to prevent the mentally unwell from making hasty decisions due to availability of guns, and their inherent high lethality. A study of unsuccessful suicide attempt patients found that nearly half had attempted to kill themselves within 20 minutes of initially deciding to commit suicide, and more than three quarters within the hour (Simon et al., 2001). The literature also suggests that the urge to self-harm often only lasts between a few minutes to a few hours (Masterson \& Klein, 2013). An additional study surveyed firearm suicide attempt survivors, and found that the vast majority noted the availability of firearms as the driving factor in electing to use a gun in their attempt, and not specifically the lethality of the weapon (Peterson et al., 1985). Importantly, about 90 per cent of people who fail in their first attempt at suicide by any means will not go on to die of suicide in the future (Owens et al., 2002). As the 
most lethal means of committing suicide, firearms tend to be permanent solutions for temporary problems. Gun availability has clearly accentuated the suicide fatality level and, as such, the literature suggests that lives can be saved through simple means prevention efforts.

There is evidence to suggest that altering the availability of the means of suicide can drastically affect the fatality rate. Three international examples in the twentieth century reveal that legislation pursuing this can work. First, the Israeli Defence Force had a high instance of firearm suicides amongst its ranks due to ease of access of firearms (Lubin et al., 2010). New measures in 2006 restricted soldiers from taking their firearms home during weekend leave, and the result was a 40 per cent reduction per annum in firearm suicides amongst Israeli soldiers. Importantly, there was no increase in the prevalence of other forms of suicides after these reforms. Similar results were also seen in Switzerland, where reforms halved the size of the national army, and greatly reduced access to guns (Reisch et al., 2013). The study found that both the firearm and overall suicide rate significantly dropped, and that there was no substantial increase in alternative methods during this period. A similar narrative was evident in the United Kingdom during the 1960s. A common method of suicide at the time involved using domestic gas to poison and suffocate oneself (Kreitman, 1976). The prominence of this method drove efforts to reduce the carbon monoxide levels in domestic gas. As the levels were lowered over time, the gas-specific and overall suicide rate in the United Kingdom dramatically declined. By curtailing the access to this means of suicide, all three countries saw a dramatic decline in suicides, and no real compensatory increase in any other method of suicide. Evidently, lives can be saved by reducing access to the most lethal means of suicide.

Small-scale efforts to introduce barriers between the suicidal and firearms have already begun across America. The majority of these programs have focused on education and awareness, or supplying gun safety devices to communities through government funding. For example, the state of New Hampshire began a program designed to educate firearm dealers to identify at-risk individuals and prevent sales after a string of firearm suicides were committed with newly purchased weapons (Vriniotis et al., 2015). The 'Gun Shop Program' was launched as a result, and the group's literature and staff training is now present in half of the state's firearm stores. Another example is a program in Alaska, which is trialling the introduction of gun safes and trigger locks in rural communities (Horn et al., 2003). A similar effort to 'suicide-proof' communities by supplying trigger locks has also been commenced in Montana (Rosston, 2014). The majority of these efforts have either been driven by grassroots organisations, or are limited by funding restrictions on state-level bodies. While the long-term impact of these campaigns cannot be measured yet, and their effectiveness hamstrung by their scale and jurisdictional boundaries, early reports appear positive. One preliminary study found that states that had introduced trigger locks experienced a lower firearm suicide and general suicide rate, although 
a direct causation remains to be proven (Anestis \& Anestis, 2015). There is evidently a delicate balancing act between gun restriction and public safety initiatives, but these examples show that compromise and cooperation is possible.

Unfortunately, well-intentioned legislation has often inadvertently undermined the ability to treat the mentally unwell, and restrict their access to guns. The first example concerns the 'prohibited persons' provisions in the Gun Control Act 1968. The original Act $(1968,1220)$ included a provision to criminalise the sale of a firearm to any person who "has been adjudicated as a mental defective or has been committed to any mental institution'. As such, the mentally unwell could be precluded from purchasing a gun today if evidence of their condition was found during a National Instant Criminal Background Check System (NICS) (Price \& Norris, 2010). Unfortunately, the Health Insurance Portability and Accountability Act 1996 (HIPAA) has severely undermined the proficiency of the background check system to investigate the mental health of gun purchasers. The 'Privacy Rule' of the Act introduced national standards pertaining to how health records could be handled by practitioners and other authorities, and severely limited the amount of 'protected health information' that could be shared (Liu et al., 2014, 10). Violations of these standards invite fines of upwards of $\$ 250,000$, and the potential for 10 years in prison (Shuren \& Livsey, 2001). By protecting the information of patients from insurance companies, the 'Privacy Rule' means practitioners now face heavy fines for disclosing medical information to the appropriate authorities. A United States Government Accountability Office Report $(2012,9)$ found that only 12 of the 50 states have made concerted efforts to make state-level mental health records available for the NICS system. Without this pathway for information to be communicated to authorities, the original intention of the Gun Control Act to preclude the mentally unwell from accessing firearms cannot be carried out.

The second issue lies with America's turbulent history with mental health treatment and in-patient care facilities. In the past, mental health patients were often treated at state-run mental health hospitals, or 'asylums' (Koyanagi, 2007, 4-9). These facilities relied on incarceration to treat their patients, and were prolific throughout the first half of the twentieth century. During the 1960s, concerns over civil rights violations and the condition of mental health hospitals drove a significant deinstitutionalisation movement. The signing of the Mental Retardation Facilities and Community Mental Health Centers Construction Act 1963 led to the shuttering of mental health hospitals across the country (Koyanagi, 2007, 10). This shift was also reflected in program funding, where efforts began to shift towards providing out-patient housing and job opportunities. Unfortunately, this shift toward deinstitutionalisation had many inadvertent effects on the broader community. Some patients were far too unwell to live in society, and were thus placed into other care centres, single-board houses where they lived without supervision, or placed with ill-prepared family members (Koyanagi, 2007, 11-12). This new paradigm 
also greatly decreased the number of publicly available hospital beds today, and this has been directly linked to an increase in suicides in a recent report by Bruckner and Yoon (2009). Without in-patient supervision, it is far easier for escalating illnesses to go unchecked, and for patients to access the means to commit suicide. In attempting to improve the treatment of the mentally unwell, legislators hamstrung an important mechanism that allowed confined treatment and thus limited access to firearms and other means of suicide during a crisis.

Efforts toward correcting these reforms are already underway. A number of the aforementioned proposals were pursued by former president Barack Obama by way of his 2013 and 2016 Executive Orders. His nuanced approach focused not on instituting greater regulation, but on providing for the proper enforcement of the current controls and laws. The 2013 package focused on clarifying the terms of the HIPAA 'Privacy Rule', and encouraged authorities to engage in further study on gun violence and provide more detailed mental health records (Ungar, 2013). The 2016 package again focused on bolstering current legislation, most notably by clarifying that NICS background checks should be expanded to 'gun shows' and other sales venues (Litchblau \& Shear, 2016). A number of these measures had been tentatively pursued in Congress by Democrats, but often failed due to strict partisan polarisation and voting behaviour. Efforts to fix America's mental healthcare system have also risen to prominence in the House of Representatives. The Helping Families in Mental Health Crisis Act (H.R. 2646) is a bipartisan bill written by former psychiatric nurses Rep. Tim Murphy and Rep. Eddie Bernice Johnson, designed to consolidate federal care programs and reform commitment procedures for at-risk individuals (Pianin, 2016). While the arena of mental health legislation has sometimes become muddied by the broader gun debate, efforts to limit access to firearms by the mentally unwell and improve treatment opportunities has regularly received broad bipartisan support from politicians and the public alike (Pew Research Center, 2015). While the effects of Obama's Executive Orders and healthcare reform initiatives like H.R. 2646 are not immediately apparent, these efforts reflect a shift toward fixing these issues with common sense legislation.

\section{Conclusion}

A crucial question emerges from this study: why would this new approach be any different? The history of gun control in America has been fraught with underperforming legislation and staunch obstructionism. There is a compelling reason to expect change, however. America's quiet epidemic of gun suicide acutely effects rural, pro-gun states in a way that gang crime and urban violence never has. A major problem in achieving consensus on gun reform in the past has been the disparate effect federal legislation has had on vastly different communities. For example, a senator from Maine is unlikely to support sweeping gun reforms 
that inconvenience their constituents on account of the high murder rate in Detroit or Chicago. Further, while failed efforts to curb gun homicide via judicial means have proven entirely ineffective, legislative responses to firearm suicides go beyond restriction or prohibition and have proved demonstrably effective in international examples. The aforementioned means prevention trial programs are all currently underway in thoroughly pro-gun states: Alaska, New Hampshire and Wyoming. While these rudimentary programs are not proven commodities at this stage, a wealth of literature supports the notion that means prevention can reduce the number of fatalities for people suffering through a mental health crisis. The next logical legislative steps_ as outlined at the conclusion of the preceding sectionare all measures that have received broad bipartisan support in recent times. Importantly, public polls repeatedly show that both Democrats and Republicans want to keep guns away from the mentally unwell (Krogstad, 2015). As the number of gun suicides continues to grow in America, means prevention legislation offers a rare nexus between the desires of 'red' and 'blue' states to achieve significant and substantial reforms that saves lives.

America's toxic relationship with guns has come to epitomise the country. With tens of thousands of deaths each year, legislators have continued to falter on effective reform that would serve to curtail the epidemic. The gun debate has become so polarised as to introduce paralysis in Congress, but there is another way. This article has demonstrated that while the current legislative agenda of gun control advocates is untenable, a new focus on preventing firearm suicides is both possible and palatable. Fundamentally, the current focus of the gun control narrative on federal restriction and regulation is unfounded, primarily because this legislation has proven to be unsuccessful, but also because it ignores the larger problem of firearm suicides. While the focus of the gun control debate has often centred on gun homicides and mass shootings, firearm suicides outnumber these incidents two-toone. Evidently, alternative approaches to legislation are necessary in order to save lives. By investigating the relevant literature, it is evident that suicide prevention is possible by implementing basic reforms that do not attempt to prohibit the general possession of guns, but instead hinder the accessibility of these weapons in times of a mental health crisis. In this way, the firearm suicide rate can be significantly reduced through legislation that is acceptable to a broad, bipartisan group. As such, pragmatism clearly must trump emotional rhetoric in the gun control debate. It's time to bite the bullet and make meaningful steps towards fixing America's quiet epidemic of firearm suicide. 


\section{Bibliography}

Anestis, Michael D. \& Anestis, Joye C. (2015). 'Suicide Rates and State Laws Regulating Access and Exposure to Handguns'. American Journal of Public Health, 105(10), 2049-2058. doi.org/10.2105/AJPH.2015.302753

Beckett, Lois. (2014, 12 September). 'The Assault Weapon Myth', New York Times. Retrieved from www.nytimes.com/2014/09/14/sunday-review/the-assaultweapon-myth.html (accessed 9 May 2016).

Brady Center. (2015). The Truth About Suicide And Guns. Retrieved from www. bradycampaign.org/sites/default/files/Truth-About-Suicide-Guns.pdf (accessed 28 January 2016).

Bruckner, T. \& Yoon, J. (2009). 'Does Deinstitutionalization Increase Suicide?'. Health Services Research, 44(4), 1385-1405. doi.org/10.1111/j.14756773.2009.00986.x

Centers for Disease Control and Prevention. (2014). 'Injury Prevention \& Control: Data \& Statistics (WISQARS)'. Retrieved from www.cdc.gov/injury/wisqars/ (accessed 7 May 2016).

Curtin, Sally C., Warner, Margaret \& Hedegaard, Holly. (2016). Increase in Suicide in the United States, 1999-2014 (NCHS Data Brief No. 241). Retrieved from www.cdc.gov/nchs/products/databriefs/db241.htm (accessed 7 May 2016).

Ehrenfreund, Max. (2015, 3 December). 'We've Had a Massive Decline in Gun Violence in the United States. Here's Why', Washington Post. Retrieved from www.washington post.com/news/wonk/wp/2015/12/03/weve-had-a-massivedecline-in-gun-violence-in-the-united-states-heres-why/ (accessed 4 March 2016).

Federal Bureau of Investigations Uniform Crime Reporting. (2014). 'Uniform Crime Report: Murder, By State, Types of Weapons, 2013'. Retrieved from www. fbi.gov/about-us/cjis/ucr/crime-in-the-u.s/2013/crime-in-the-u.s.-2013/tables/ table-20/table_20_murder_by_state_types_of_weapons_2013.xls (accessed 2 May 2016).

Fischer, Claude. (2011, 2 May). 'A Crime Puzzle', The Public Intellectual. Retrieved from thepublicintellectual.org/2011/05/02/a-crime-puzzle/ (accessed 16 March 2016).

Florida, Richard. (2011, 13 January). 'The Geography of Gun Deaths', The Atlantic. Retrieved from www.theatlantic.com/national/archive/2011/01/the-geographyof-gun-deaths/69354/ (accessed 29 January 2016). 
Gun Control Act of 1968, Public Law 90-618. Retrieved from www.gpo.gov/fdsys/ pkg/STATUTE-82/pdf/STATUTE-82-Pg1213-2.pdf (accessed 4 May 2016).

Health Insurance Accountability and Portability Act of 1996, Public Law 104-191. Retrieved from www.gpo.gov/fdsys/pkg/PLAW-104publ191/html/PLAW-104 publ191.htm (accessed 4 May 2016).

Horn, A., Grossman, D.C., Jones, W. \& Berger, L.R. (2003). 'Community Based Program to Improve Firearm Storage Practices in Rural Alaska', Injury Prevention 9(1), 231-234. doi.org/10.1136/ip.9.3.231

Kalesan, Bindu, Villarreal, Marcos D., Keyes, Katherine M. \& Galea, Sandro. (2015). 'Gun Ownership and Social Gun Culture'. Injury Prevention, 22(3). dx.doi.org/10.1136/injuryprev-2015-041586

Koyanagi, Chris. (2007). 'Learning From History: Deinstitutionalization of People with Mental Illness As Precursor to Long-Term Care Reform' (Kaiser Commission on Medicaid and the Uninsured). Retrieved from kaiserfamilyfoundation.files. wordpress.com/2013/01/7684.pdf (accessed 4 May 2016).

Kreitman, N. (1976). 'The coal gas story. United Kingdom suicide rates, 1960-71'. British Journal of Preventative and Social Medicine, 30(2), 86-93.

Krogstad, Jens M. (2015, 21 October). 'Gun Homicides Steady after Decline in '90s; Suicide Rate Edges Up'. Pew Research Center. Retrieved from www.pewresearch. org/fact-tank/2015/10/21/gun-homicides-steady-after-decline-in-90s-suiciderate-edges-up/ (accessed 3 March 2016).

Krouse, William. (2015). Mass Murder with Firearms: Incidents and Victims, 1999-2013. Washington, DC: United States Congressional Research Service.

Levitt, Steven D. (2004). 'Understanding Why Crime Fell in the 1990s: Four Factors That Explain The Decline and Six That Do Not'. Journal of Economic Perspectives, 18(1), 163-190. doi.org/10.1257/089533004773563485

Litchblau, Eric \& Shear, Michael D. (2016, 6 January). 'Tearful Obama Outlines Steps to Curb Gun Deaths', New York Times. Retrieved from www.nytimes. com/2016/01/06/us/politics/obama-gun-control-executive-action.html?_r=0 (accessed 27 January 2016).

Liu, E., Bagalman, E., Chu, V. \& Redhead, S.C. (2014). Submission of Mental Health Records to NICS and the HIPAA Privacy Rule. Washington, DC: United States Congressional Research Service. 
Lubin G., Werbeloff N., Halperin D., Shmushkevitch M., Weiser M. \& Knobler H.Y. (2010). 'Decrease in Suicide Rates after a Change of Policy Reducing Access to Firearms in Adolescents: A Naturalistic Epidemiological Study', Suicide and Life Threatening Behaviour 40(5), 421-424. doi.org/10.1521/suli.2010.40.5.421

Masterson, J.F. \& Klein, R. (2013). Psychotherapy Of The Disorders Of The Self. Abingdon, UK: Taylor \& Francis.

Miller, Matthew, Azrael, Deborah \& Hemenway, David. (2002). 'Household Firearm Ownership Levels and Homicide Rates Across U.S. Regions and States, 1988-1997'. American Journal of Public Health, 92(12), 1988-1993. doi. org/10.2105/AJPH.92.12.1988

Miller, Matthew, Molnar, Beth, Barber, Catherine, Hemenway, David \& Azrael, Deborah. (2009). 'Recent Psychopathology, Suicidal Thoughts and Suicide Attempts in Households with vs. without Firearms: Finding from the National Comorbidity Study Replication'. Injury Prevention, 15(3), 183-187. doi. org/10.1136/ip.2008.021352

Miller, Matthew, Barber, Catherine, White, Richard A. \& Azrael, Deborah. (2013). 'Firearms and Suicide in the United States: Is Risk Independent of Underlying Suicidal Behaviour?' American Journal of Epidemiology, 176(6), 946-955. doi. org/10.1093/aje/kwt197

Monroe, Jeffrey D. (2008). Homicide and Gun Control: The Brady Handgun Violence Prevention Act and Homicide Rates. New York, NY: LFB Scholarly Publishing.

Owens, D., Horrocks, J. \& House, A. (2002). 'Fatal and non-fatal repetition of self-harm: systematic review' British Journal of Psychiatry, 181(1), 193-199. doi. org/10.1192/bjp.181.3.193

Peterson, L., Peterson, M., O’Shanick, G. \& Swann, A. (1985). 'Self-inflicted Gunshot Wounds: Lethality of Method Versus Intent'. American Journal of Psychiatry, 142(1), 228-231.

Pew Research Center. (2015, August). 'Continued Bipartisan Support for Expanded Background Checks on Gun Sales'. Retrieved from www.people-press.org/ files/2015/08/08-13-15-Guns-release.pdf (accessed 6 April 2016).

Pianin, Eric. (2016, 19 April). 'How Gun Control Politics Is Delaying Major Mental Health Reform', Fiscal Times. Retrieved from www.thefiscaltimes. com/2016/04/19/How-Gun-Control-Politics-Delaying-Major-Mental-HealthReform (accessed 25 April 2016).

Price, M. \& Norris, D.M. (2010). 'Firearm laws: a Primer for Psychiatrists'. Harvard Review of Psychiatry, 18(6), 326-335. doi.org/10.3109/10673229.2010.527520 
Reisch, Thomas, Steffen, Timur, Habenstein, Astrid \& Tschacher, Wolfgang. (2013). 'Change in Suicide Rates in Switzerland Before and After Firearm Restriction Resulting From the 2003 "Army XXI” Reform'. American Journal of Psychiatry, 170(9), 977-984.

Reyes, Jessica W. (2007). 'Environmental Policy as Social Policy? The Impact of Childhood Lead Exposure on Crime'. National Bureau of Economic Research (Working Paper No. 13097). Retrieved from www.nber.org/papers/w13097 (accessed 3 May 2016).

Rosston, Karl. (2014). 'Suicide Prevention in Montana: Legislative Update'. Retrieved from leg.mt.gov/content/Committees/Interim/2013-2014/ChildrenFamily/Meetings/August-2014/rosston-suicide-prevention-powerpointaug2014.pdf (accessed 25 April 2016).

Sanger-Katz, Margot. (2015, 9 October). 'Gun Deaths Are Mostly Suicides', New York Times. Retrieved from www.nytimes.com/2015/10/09/upshot/gun-deathsare-mostly-suicides.html?referer $=($ accessed 2 February 2016).

Short, Kathleen. (2014). 'The Supplemental Poverty Measure: 2013'. Retrieved from www.census.gov/content/dam/Census/library/publications/2014/demo/ p60-251.pdf (accessed 3 May 2016).

Shuren, A.W. \& Livsey, K. (2001). 'Complying with the Health Insurance Portability and Accountability Act'. American Association of Health Nurses Journal, 49(11), 501-507.

Siegel, Michael, Ross, Craig S. \& King, Charles. (2013). 'The Relationship Between Gun Ownership and Firearm Homicide Rates in the United States, 1981-2010'. American Journal of Public Health, 103(11), 2098-2105. doi.org/10.2105/ AJPH.2013.301409

Simon, T.R., Swann, A.C., Powell, K.E., Potter, L.B., Kresnow, M. \& O’Carroll, P.W. (2001). 'Characteristics of Impulsive Suicide Attempts and Attempters'. Suicide and Life Threatening Behaviour, 32(1), 49-59. doi.org/10.1521/ suli.32.1.5.49.24212

Sullum, Jacob. (2015, 2 September). 'Do Strict Firearm Laws Give States Lower Gun Deaths?' [Blog post]. Retrieved from reason.com/blog/2015/09/02/dostrict-firearm-laws-give-states-lower (accessed 28 January 2016).

Tavernise, Sabrina. (2013, 13 February). 'To Reduce Suicide Rates, New Focus Turns to Guns', New York Times. Retrieved from www.nytimes.com/2013/02/14/us/ to-lower-suicide-rates-new-focus-turns-to-guns.html?_r=0 (accessed 21 January 2016). 
Ungar, Rick. (2013, 6 January). 'Here Are the 23 Executive Orders on Gun Safety Signed Today By The President', Forbes. Retrieved from www.forbes.com/sites/ rickungar/2013/01/16/here-are-the-23-executive-orders-on-gun-safety-signedtoday-by-the-president/\#7532a6c47cff (accessed 3 May 2016).

United States Census Bureau. (2014). 'Annual Estimates of the Resident Population: April 1, 2010 to July 1, 2013'. Retrieved from factfinder.census.gov/bkmk/ table/1.0/en/PEP/2013/PEPANNRES (accessed 28 April 2016).

United States Department of Justice. (2001). 'Firearm Use by Offenders: Survey of Inmates in State and Federal Correctional Facilities', Bureau of Justice Statistics Special Report. Retrieved from www.bjs.gov/content/pub/pdf/fuo.pdf (accessed 4 March 2016).

United States Department of Labor. (n.d.). 'Local Area Unemployment Statistics, 2013', Bureau of Labor Statistics. Retrieved from www.bls.gov/lau/lastrk13.htm (accessed 4 May 2016).

United States Government Accountability Office. (2012). 'Gun Control: Sharing Promising Practices and Assessing Incentives Could Better Position Justice to Assist States in Providing Records for Background Checks'. Retrieved from www.gao.gov/assets/600/592452.pdf (accessed 10 May 2016).

Vriniotis, Mary, Barber, Catherine, Frank, Elaine \& Demicco, Ralph. (2015). 'A Suicide Prevention Campaign For Firearm Dealers In New Hampshire'. Suicide And Life Threatening Behaviour, 45(2), 157-163. doi.org/10.1111/sltb.12123

Vyrostek, Sara B., Annest, Joseph L. \& Ryan, George W. (2001). 'Surveillance for Fatal and Nonfatal Injuries-United States, 2001'. Retrieved from www.cdc. gov/mmwr/preview/mmwrhtml/ss5307a1.htm (accessed 4 May 2016). 
This text is taken from The ANU Undergraduate Research Journal, Volume Eight, 2016, edited by Daniel McKay, published 2017 by ANU eView, The Australian National University, Canberra, Australia.

dx.doi.org/10.22459/AURJ.08.2016.06 